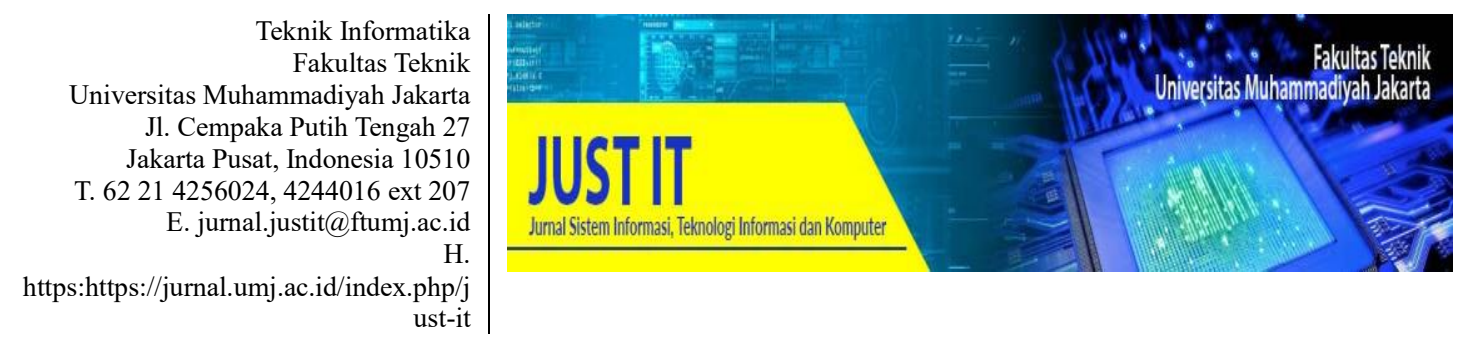

\title{
PEMODELAN DAN SIMULASI PROSES PRODUKSI PERALATAN BAYI PADA HOME INDUSTRI PUPPY PUTRA PERDANA
}

\author{
Tazkia Shabrina Az-zahra ${ }^{1}$,Trisha Aida Syahputri ${ }^{2}$, Niken Ayu Setifani ${ }^{3}$, Kinanti \\ Prawita Ningrum ${ }^{4}$ dan Dwi Rolliawati ${ }^{5}$ \\ ${ }^{12345}$ Teknologi Fakultas Sains dan Teknologi UIN Sunan Ampel Surabaya
}

h06217021@uinsby.ac.id ${ }^{1}$,trishaidas@gmail.com², nikenayustef@gmail.com ${ }^{3}$,kinantiprawitan27@gmail.com ${ }^{4}$,dwi-roll@uinsby.ac.id ${ }^{5}$

\begin{abstract}
Abstrak
Puppy Putra Perdana merupakan salah satu home industry yang bergerak dibidang konveksi, khususnya produksi produk peralatan bayi yang ada di Surabaya. Penelitian ini bertujuan untuk menganalisis efisiensi dari model dan simulasi produksi Puppy Putra Perdana dan menyarankan model produksi yang lebih baik. Metode pada penelitian ini memiliki tahapan yang meliputi analisis permasalahan, studi literatur dan pemodelan. Analisis dan pemodelan pada produksi barang di Home industry Puppy Putra Perdana dapat ditarik informasi bahwa produksi saat ini kurang efisien, permasalahan yang dialami oleh Home Industry Puppy Putra Perdana adalah kurangnya manajemen produksi sehingga terjadi antrian akibat dari proses produksi yang lama, hal tersebut dikarenakan produksi menggunakan sistem make to order. Model produksi yang disarankan peneliti untuk diterapkan pada Puppy Putra Perdana memiliki efisiensi lebih jika dibandingkan dengan proses produksi yang diterapkan saat ini, sehingga dapat membuat proses produksi menjadi lebih baik dan memberikan keunggulan pada Puppy Putra Perdana.
\end{abstract}

Kata Kunci:supply chain, pemodelan, home industry

\begin{abstract}
Puppy Putra Perdana is one of the home industry engaged in convection, especially the production of baby equipment products in Surabaya. This study aims to analyze the efficiency of the Puppy Putra Perdana production model and simulation and suggest a better production model. The method in this research has stages which include problem analysis, literature study and modeling. Analysis and modeling on the production of goods in the Puppy Putra Perdana Home industry can be drawn information that the current production is less efficient, the problem experienced by the Puppy Putra Perdana Home Industry is the lack of production management so that there is a queue due to the long production process, it is because the production uses make to order system. Production models that are suggested by researchers to be applied to Puppy Putra Perdana have more efficiency when compared to the current production process, so they can make the production process better and give advantages to Puppy Putra Perdana.
\end{abstract}

Keywords: supply chain, modeling, home industry 


\section{PENDAHULUAN}

Kebutuhan masyarakat Indonesia semakin hari semakin beragam. Hal ini memunculkan semakin beragamnya industri atau perusahaan baru untuk memenuhi permintaan pasar dari beragam kebutuhan tersebut. Hal itu membuat pengusaha dituntut untuk berpikir kreatif dengan menciptakan inovasi yang terbaru bagi produknya. Tak terkecuali bagi home industry . Pemusatan kegiatan produksi home industry biasa dipusatkan di rumah, hampir seperti UMKM atau usaha kecil dan menengah. Pengertian home industry juga dijelaskan dalam UU No. 20 Tahun 2008 tentang Usaha Mikro Kecil Menengah, bahwa usaha kecil adalah usaha dengan kekayaan bersih paling banyak Rp.200 juta (tidak termasuk tanah dan bangunan tempat usaha) dengan hasil penjualan tahunan paling banyak Rp. 1 Milyar(UU No. 20 Tahun 2008, 2008).(11/MIND/PER/3/2014, 2014)Kriteria industri kecil dan menengah juga terdapat pada Peraturan Menteri Pasal 3, yaitu:

a. Industri kecil yaitu industri dengan nilai investasi paing banyak Rp. 500.000.000,(lima ratus juta rupiah), tidak termasuk tanah dan bangunan tempat usaha; dan

b. Industri menengah yaitu industri dengan nilai investasi lebih besar dari Rp. 500.000.000,- (lima ratus juta rupiah) atau paling banyak 10.000.000.000,(sepuluh miliar rupiah), tidak termasuk tanah dan bangunan tempat usaha.

Saputro mengamati bahwa UMKM di Indonesia sangat berpengaruh terhadap PDB (Produk Domestik Bruto) nasional sebanyak $55.56 \%$, ini didasari oleh data pada tahun 2008, Biro Perencanaan Kementerian Negara Koperasi dan UKM Republik Indonesia(Suci, 2017). Puppy Putra Perdana merupakan salah satu home industry yang bergerak dibidang konveksi, khususnya produksi produk peralatan bayi yang ada di Surabaya. Konsumen Puppy tersebar di berbagai wilayah di Indonesia, salah satunya di Surabaya hingga Banjarmasin.

Home industry Puppy Putra Perdana melakukan kegiatan produksinya di rumah, dengan dibantu oleh dua orang pegawai dan beberapa alat mesin. Produk yang dibuat oleh Puppy diantaranya adalah bantal bayi, guling bayi dan kasur bayi. Puppy mengerjakan produksi berdasarkan pesanan yang diterima dalam sehari. Jika ada pesanan masuk maka Home Industry Puppy akan mulai memproduksinya. Tahapan produksinya sendiri dimulai dari pembelian bahan baku lalu dilanjut dengan pemotongan bahan.

Dengan memperhatikan optimasi proses produksi, maka biaya pengeluaran perusahaan untuk kegiatan produksi dapat ditekan. namun tetap tidak mengabaikan kualitas hasil produksi itu sendiri. Banyak cara yang dapat dilakukan untuk merencanakan optimasi proses produksi yang sesuai dengan pola kerja suatu perusahaan seperti home industry Puppy. salah satu cara yang dapat ditempuh adalah dengan membuat simulasi.

Simulasi merupakan suatu metodologi untuk melaksanakan percobaan dengan menggunakan model dari suatu sistem yang nyata. Simulasi telah banyak digunakan pada berbagai macam penelitian, dan terbukti dapat memecahkan suatu masalah. Simulasi dapat menghemat waktu, biaya, tenaga karena tidak perlu langsung mengimplementasikan suatu percobaan ke kenyataan, tetapi bisa melalui simulasi terlebih dahulu.

Penelitian terdahulu yang berkaitan dengan pemodelan dan simulasi dilakukan oleh Philip Faster Eka Adipraja dan Danang Arbian Sulistyo dalam jurnal yang berjudul "Pemodelan Sistem Dinamik untuk Prediksi Intensitas Hujan Harian di Kota Malang" meneliti mengenai prediksi intensitas hujan harian pada tahun 2018-2020 yang nantinya dapat digunakan oleh pihak yang berwenang untuk mengurangi kerugian korban yang mungkin terjadi disebabkan oleh bencana banjir. Penelitian ini memiliki hasil validasi model intensitas hujan yang mempunyai nilai error $E 1$ sebesar $3.86 \%$ dan $E 2$ sebesar 4.13\% dengan hasil RMSE menunjukkan angka 8.4452(Adipraja \& Sulistyo, 2018). Ini membuktikan bahwa banyak manfaat yang dapat diambil dari penggunaan dari pemodelan dan simulasi.

Penelitian ini dilakukan karena home industry Puppy masih belum menerapkan strategi produksi yang pas, sehingga pembuatan simulasi diharapkan dapat membantu optimasi produksi home industry 
Puppy. Pengsimulasian menggunakan AnyLogic 48.5.0 Personal Learning Edition untuk membuat pemodelan dan simulasi dari proses produksi Toko Perlengkapan Bayi Puppy, mulai dari bahan-bahan baku didapatkan dari distributor, proses menggunting kain, menjahit hingga pengiriman.

\section{LANDASAN TEORI}

Home industry merupakan tempat bagi banyak orang yang dapat tumbuh dan berkembang secara independen dengan memberikan pengaruh besar serta memiliki peran strategis dalam pembangunan ekonomi.(Susana, 2012)

Home industry adalah kegiatan usaha yang dapat membuka lapangan kerja dan memberikan pelayanan ekonomi secara luas kepada orang lain, dan memiliki peran dalam meningkatkan kesejahteraan masyarakat, menekan angka pengangguran. (Susana, 2012)

Dalam KBBI, model merupakan sebuah pola contoh, acuan, ragam dan lain-lain dari sesuatu yang akan dihasilkan. Menurut Daellenbach (1994) model adalah suatu perwakilan atau abstraksi dari sebuah objek atau situasi aktual.Menurut KBBI, simulasi adalah metode pelatihan yang meragakan suatu hal menjadi bentuk tiruan yang hampir sama dengan keadaan sebenarnya. (KBBI). Sedangkan, menurut Banks et al (2004) simulasi adalah replika proses operasi dari sebuah kondisi sesungguhnya atau sistem dari waktu ke waktu. Simulasi adalah konstruksi dari suatu model dan penggunaan model secara uji coba untuk menelaah suatu sistem. Pendapat lain menyatakan simulasi merupakan proses perancangan model matematis atau logis dari sistem untuk diterapkan eksperimen pada model tersebut untuk menggambarkan, menjelaskan, dan memprediksi perilaku dari sistem. Simulasi erat kaitannya dengan model berbasis komputer(Saputri, Nugraha, \& Amila, 2014). Menurut Sridadi pada Mahessya Raja pemodelan dan simulasi adalah salah satu alat yang sering digunakan untuk mempelajari atau menganalisis kinerja dari suatu sistem atau proses (Mahessya, 2017).

Supply chain management (SCM) adalah kegiatan mengelola kegiatan dari memperoleh bahan mentah, mengubah bahan mentah menjadi barang dalam proses kemudian mengubah barang dalam proses menjadi barang jadi kemudian mengirimkan produk tersebut kepada konsumen melalui sistem distribusi (Irawan, 2008). Pendapat lain mendefinisikan Supply Chain Management (SCM) sebagai integrasi proses bisnis utama dari konsumen hingga pemasok yang menyediakan produk, layanan, dan informasi dan karenanya menambah nilai bagi pelanggan dan pemangku kepentingan lainnya (Agarwal, Shankar, \& Mandal, 2006). Tujuan dari SCM adalah untuk membuat kegiatan yang diawali dari suppliers, manufactures, warehouse hingga stores agar dapat berjalan dengan efektif dan efisien.

Produksi merupakan kegiatan mengubah input menjadi output, yang dimana isinya seluruh aktifitas atau kegiatan menghasilkan barang dan jasa, serta kegiatankegiatan lain yang mendukug atau usaha untuk menghasilkan produksi tersebut (Herawati \& Mulyani, 2016).

Anylogic merupakan sebuah alat pemodelan simulasi yang dikembangkan oleh The Anylogic Company. Tools ini merupakan sebuah software simulasi lintas platform yang dapat berjalan pada Windows, Linux dan MacOS.

\section{METODE}

Penelitian ini tersusun dari beberapa tahapan yang sistematis.

A. Analisis Permasalahan

Tahap analisis permasalahan merupakan tahapan untuk menganalisis kondisi yang terjadi pada fase industri milik Perusahaan Home Industry Puppy Putra Perdana. Dalam mengumpulkan data, peneliti menggunakan metode wawancara kepada narasumber terpercaya yaitu pemilik perusahaan dan melakukan observasi langsung ke lokasi produksi peralatan bayi oleh perusahaan tersebut.

B. Studi Literatur

Setelah menganalisis permasalahan, peneliti melakukan tahap selanjutnya yaitu membaca referensi dari buku dan 
penelitian terdahulu untuk mencari solusi permasalahan yang telah dijabarkan pada analisis permasalahan. Dari membaca referensi ini peneliti dapat menemukan solusi yang tepat.

C. Pemodelan

Tahap yang dilakukan setelah studi literatur yaitu tahap pemodelan, disini tahap pemodelan yaitu menggambarkan model yang sesuai dengan hasil analisis permasalahan dan studi literatur yang telah dilakukan. Penelitian ini merupakan simulasi dinamis yang artinya simulasi model yang dipengaruhi dengan waktu. Penelitian ini menggunakan aplikasi anylogic untuk membantu dalam menggambarkan model yang ada. Untuk proses yang lebih lengkap akan dijabarkan di bawah:

1. Mengidentifikasi proses produksi peralatan bayi Puppy Putra Perdana. Mengidentifikasi proses produksi dapat dilakukan dengan wawancara dan observasi langsung.

2. Memodelkan proses produksi. Memodelkan proses produksi yaitu tahap dimana menggambarkan model dari proses produksi, disini penulis menggunakan aplikasi anylogic.

\section{HASIL DAN PEMBAHASAN}

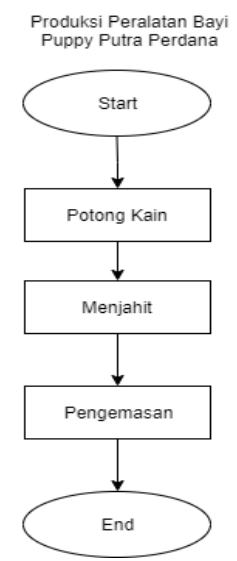

Gambar 1. Flowchart Alur Produksi

Flowchart Alur Produksi

Alur proses produksi peralatan bayi Puppy Putra Perdana diawali dengan menyiapkan bahan dan memotong kain, jumlah dari memotong kain disini sesuai dengan pesanan dari pesanan pelanggan berapa jumlah bantal, kasur dan guling yang dipesan. Setelah kain dipotong, langkah selanjutnya adalah kain hasil potong dijahit. Langkah terakhir sebelum produksi selesai, produk dikemas sesuai dengan kemasan yang seharusnya dan kemudian proses produksi selesai.

Pemodelan dan Simulasi

Table 1 Proses pada Puppy Putra Perdana

\begin{tabular}{|c|c|c|}
\hline Proses & Elemen Proses & Delay Time \\
\hline Source & $\begin{array}{ll}\text { Barang } & \text { yang } \\
\text { diproduksi: } & \\
\bullet & \text { Guling } \\
\text { - } & \text { Bantal } \\
\text { - } & \text { Kasur }\end{array}$ & \\
\hline Production & Memotong Kain & $\begin{array}{l}\text { uniform }(1,1) \\
\text { days }\end{array}$ \\
\hline Production & Menjahit & $\begin{array}{l}\text { triangular }(1,2,5) \\
\text { days }\end{array}$ \\
\hline Production & Pengemasan & $\begin{array}{l}\text { uniform }(1,2) \\
\text { days }\end{array}$ \\
\hline
\end{tabular}

Pengelompokan data elemen proses serta waktu yang dibutuhkan digambarkan pada Tabel 1. Data yang ditampilkan pada Tabel 1 merupakan hasil dari observasi dan wawancara kepada narasumber. Bahan baku dibeli setelah ada pesanan masuk, pemasok bahan baku berada di Surabaya sehingga produsen tidak membutuhkan waktu lama untuk memenuhi kebutuhan bahan baku. Untuk pembuatan produk-produk pada home industry Puppy Putra Perdana melibatkan proses:

1. Menerima pesanan, produk yang tersedia yaitu guling, bantal dan kasur. Produsen membeli bahan baku sesuai yang dibutuhkan pesanan.

2. Setelah bahan baku tersedia, proses selanjutnya adalah proses produksi memotong kain.

3. Proses Production Memotong Kain melibatkan dua mesin dan dua pekerja. Proses ini memerlukan waktu 1 hari.

4. Proses Production Menjahit melibatkan dua mesin dan dua pekerja. Proses ini membutuhkan waktu 1-5 hari. 
5. Proses Production Pengemasan melibatkan dua pekerja, memerlukan

waktu 1-2 hari.

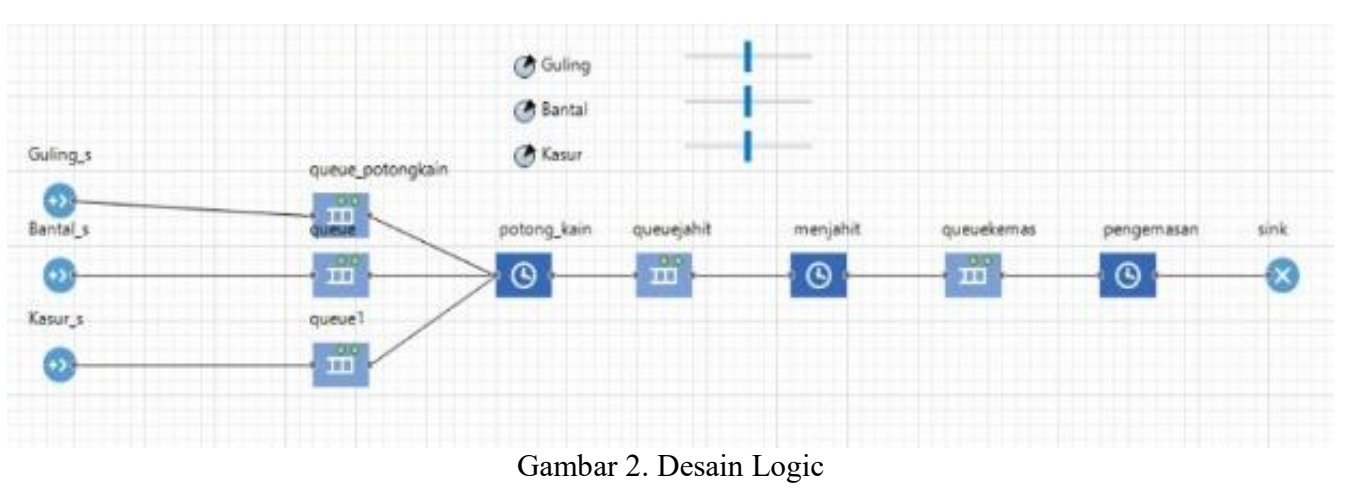

Pada sistem produksi ini terdapat hanya 1 bagian logic dengan tiga source yaitu bantal, guling dan kasur. Ketiga source tersebut masing-masing memiliki bahan baku yang sama.Desain logic ini mulai dari proses produksi produk hingga proses pengiriman produk.

Di awal proses pada desain logic terdapat tiga jalur, karena terdapat tiga source berbeda yang masing-masing memiliki queue potong kain. Karena proses dan bahan yang digunakan sama untuk semua source, maka dijadikan satu jalur setelah queue potong kain dan dimulai dari proses potong kain.

Proses selanjutnya yaitu masuk ke queue jahit, digunakan untuk kain yang sudah dipotong menunggu untuk masuk proses jahit. Setelah proses jahit terdapat queue kemas. Di queue kemas ini adalah kain-kain yang sudah dijahit mengantri untuk proses pengemasan. Jika sudah selesai dikemas, produk-produk siap dikirim ke pelanggan yang memesan.

Pemodelan yang dibuat berdasarkan sistem yang saat ini diterapkan dalam proses produksi di Home industri Pupy Putra Perdana. Pembuatan produk dibuat berdasarkan toko yang pertama kali memesan barang. Hal ini menyebabkan banyaknya antrian pada proses produksi karena lamanya proses produksi barang yang dilakukan.
Misalnya, ada 3 toko yang memesan barang dengan jumlah yang berbeda. Toko A memesan 10 guling dan 3 kasur. Toko memesan B 3 guling dan 5 bantal. Terakhir, toko $\mathrm{C}$ memesan 5 bantal dan 2 kasur. Home industry Puppy Putra Perdana akan memproses pesanan dari toko A terlebih dahulu dengan barang guling dan kasur, setelah barang sudah siap jadi maka baru pesanan dari toko $\mathrm{B}$ dan $\mathrm{C}$ akan dikerjakan. Padahal, toko B dan $\mathrm{C}$ memesan barang yang salah satunya sama.

Diagram pada model ini menggambarkan dengan input guling sebanyak 29, bantal 30 dan kasur 14 menghasilkan output yang hanya berjumlah 61, diagram dengan model seperti ini tidak menunjukkan variasi pada outputnya. Apabila input terlalu banyak maka jumlah output yang keluar semakin sedikit karena lamanya proses produksi. Sehingga pada sistem yang berjalan saat ini dirasa kurang dalam memanejemen pemesanan pada produksi. Berdasarkan pemaparan dan desain logic diatas, Gambar 2, 3 dan 4 merupakan hasil pemodelan dan simulasi dalam bentuk 2 Dimensi dan 3 Dimensinya 


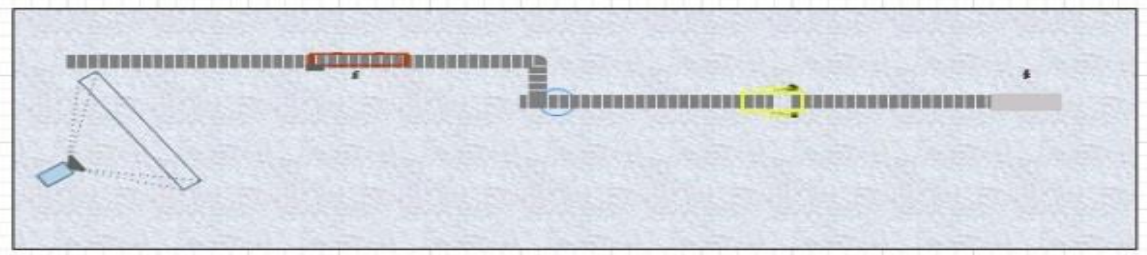

Gambar 3. Desain 2D

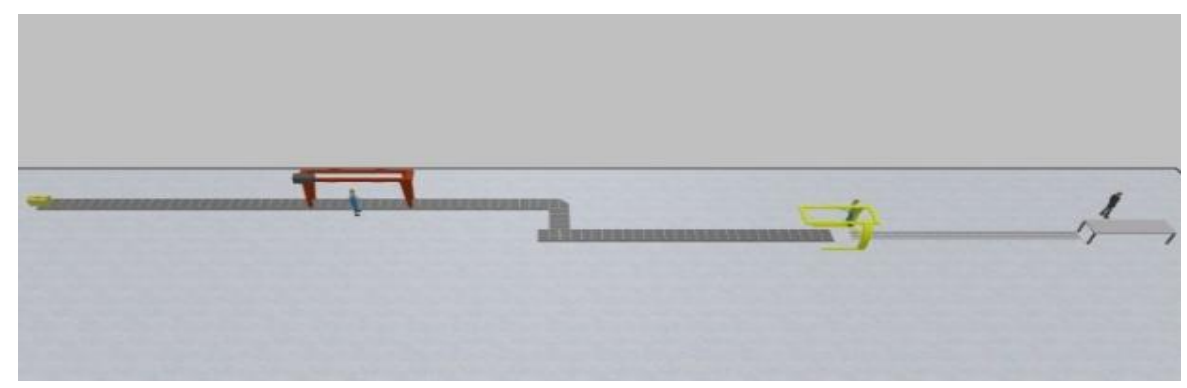

Gambar 4. Desain 3D

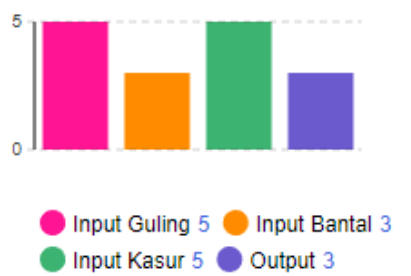

Berdasarkan dari pemodelan real, peneliti membuat pemodelan lain yang bisa dipertimbangkan utuk alternatif skenario produksi.

Gambar 5 Grafik Produksi

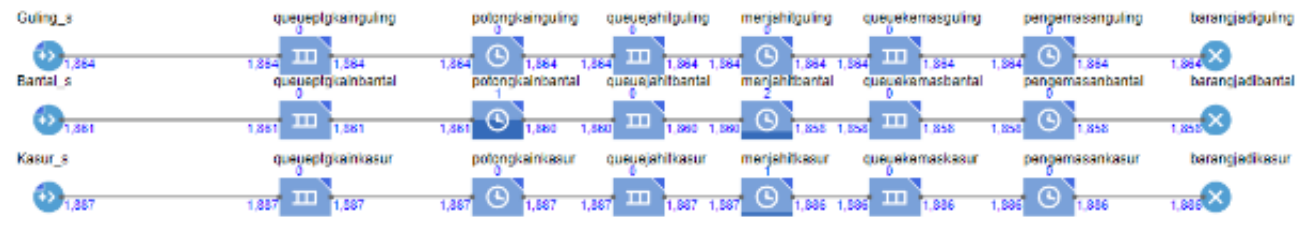

Gambar 6. Pemodelan Saran

Pemodelan yang disarankan adalah dengan masing-masing dari produk dikerjakan tidak di waktu yang sama. Sehingga tidak terjadi tabrakan antara produk yang dibuat. Dengan model seperti itu, menghasilkan diagram yang menggambarkan jika jumlah produk guling yang dibuat yaitu sebanyak 1864 maka jumlah produk yang dihasilkan menjadi barang jadi yaitu juga 1864, jika jumlah produk bantal yang dibuat yaitu sebanyak 1861 maka jumlah produk yang dihasilkan menjadi barang jadi yaitu 1858 dan jika jumlah produk kasur yang dibuat yaitu

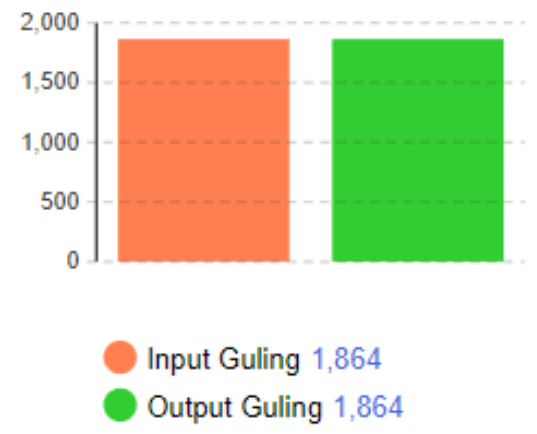

Gambar 7. Grafik Produksi Guling sebanyak 1887 maka akan menghasilkan produk jadi yaitu sebanyak 1886 . 


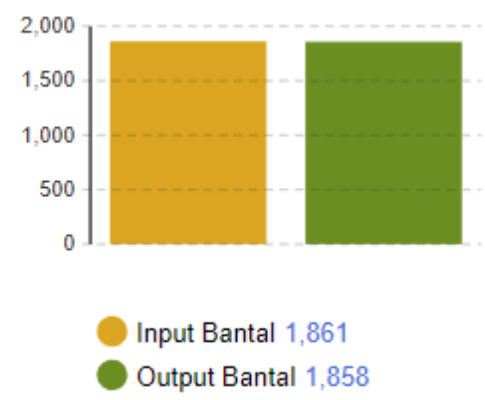

Gambar 8 Grafik Produksi Bantal

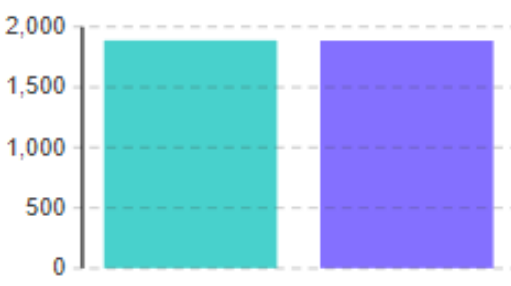

Input Kasur 1,887

Output Kasur 1,886

Gambar 9. Grafik Produksi Kasur

Dari ketiga diagram tersebut menunjukkan bahwa di tiap-tiap produksi tidak menghasilkan perbedaan yang cukup jauh dengan produk yang jadi, sehingga dengan model seperti ini akan terlihat lebih efisien dikarenakan tidak menimbulkan antrian tiap produknya terlalu padat. Hal ini dikarenakan setiap pekerja lebih fokus pada bidang masing-masing dan tidak terjadi campuran antara barang satu dan lainnya.

Dari dua pemodelan diatas, terdapat beberapa perbedaan yang terlihat diantaranya adalah perbedaan segi prosedur pengerjaan, segi efisiensi waktu dan dari segi pengadaan sumber daya. Pemodelan pertama adalah pemodelan sesungguhnya yang sampai saat ini digunakan di Home Industry Puppy Putra Perdana. Home industry ini menerima beberapa pesanan terlebih dahulu baru kemudian mengerjakannya secara tiap pesanan dengan prinsip First in First Out. Jadi, meskipun pesanannya beraneka ragam tetap di kerjakan dahulu pesanan yang pertama datang, baru kemudian mengerjakan pesanan selanjutnya. Dari prosedur yang ada, dapat dilihat bahwa tingkat efisiensi pengerjaannya kurang, dikarenakan pengerjaan secara per pesanan meskipun pesanannya bermacammacam produk. Disini juga terdapat sumber daya seperti mesin dan alat serta beberapa pekerja yang juga mempunyai keterbatasan dalam mengolah bahan baku.

Sedangkan, pemodelan kedua ini dikerjakan menurut produk. Misalnya pesanan A dan B sama-sama terdapat pesanan bantal. Maka kedua pesanan tersebut untuk produk bantal dilakukan satu kali proses pengerjaan sehingga waktu yang ada bisa dimanfaatkan dengan baik dan bukan berdasarkan pesanan seperti proses sebenarnya. Jadi untuk sekali proses itu mengerjakan satu jenis produk pesanan. Jika terdapat lebihan dari satu kali proses tersebut, maka bisa disimpan sebagai stok untuk bisa digunakan sebagai pemenuhan pesanan yang akan datang. Untuk masalah efisiensi produksi juga bisa dengan menambahkan mesin produksi namun, hal itu membutuhkan biaya yang banyak.

\section{KESIMPULAN}

Analisis dan pemodelan pada produksi barang di Home Industry Puppy Putra Perdana yang sedang berjalan saat ini menghasilkan informasi bahwa permasalahan yang dialami oleh Home Industry Puppy Putra Perdana adalah kurang efisiennya proses produksi dikarenakan proses pembuatannya menggunakan sistem make to order, sehingga menimbulkan terjadinya antrian akibat dari proses produksi yang lama. Proses produksi tersebut membutuhkan waktu yang lama akibat pelayanan produk berdasarkan permintaan masing-masing toko.

Berdasarkan pemaparan sistem yang sedang berjalan, peneliti memberikan saran bahwa proses produksi dilakukan dengan mengerjakan produk yang sejenis agar proses produksi lebih efisien karena dapat menimbulkan antrian tiap produknya tidak terlalu padat, hal ini dapat terjadi karena pekerja akan lebih fokus dengan bidangnya masing-masing. 


\section{DAFTAR PUSTAKA}

11/M-IND/PER/3/2014, P. M. P. N. Peraturan Menteri Perindustrian Nomor $11 / M$ IND/PER/3/2014. , (2014).

Adipraja, P. F. E., \& Sulistyo, D. A. (2018). Pemodelan Sistem Dinamik untuk Prediksi Intensitas Hujan Harian di Kota Malang. Jurnal Ilmiah Teknologi Informasi Asia, 12(2), 137. https://doi.org/10.32815/jitika.v12i2.27 2

Agarwal, A., Shankar, R., \& Mandal, P. (2006). Effectiveness of information systems in supply chain performance: a system dynamics study. International Journal of Information Systems and Change Management, 1(3), 241-261. https://doi.org/10.1504/IJISCM.2006.01 1198

Herawati, H., \& Mulyani, D. (2016). PENGARUH KUALITAS BAHAN BAKU DAN PROSES PRODUKSI TERHADAP KUALITAS PRODUK PADA UD. TAHU ROSYDI PUSPAN MARON PROBOLINGGO Herlin. Prosiding Seminar Nasional, ISBN 978$6,463-482$.

Irawan, A. P. (2008). Buku Ajar Manajemen Rantai Pasokan. Fakultas Teknik Universitas Tarumanagara.
Mahessya, R. A. (2017). Pemodelan Dan Simulasi Sistem Antrian Pelayanan Pelanggan Menggunakan Metode Monte Carlo Pada Pt Pos Indonesia (Persero) Padang. Jurnal Ilmu Komputer, 6(1), $15-24$.

https://doi.org/10.33060/jik/2017/vol6.is s1.41

Saputri, T., Nugraha, C., \& Amila, K. (2014). Model Simulasi Untuk Pergerakan Kendaraan. Jurnal Online Intitut Teknologi Nasional, 02(04), 12-24.

Suci, Y. R. (2017). Development of MSME (Micro, Small and Medium Enterprises) in Indonesia. Jurnal Ilmiah Cano Ekonomos, 6(1), 51-58.

Susana, S. (2012). Peranan Home Industri Dalam Meningkatkan Kesejahteraan Masyarakat Menurut Perspektif Ekonomi Islam ( Studi Kasus Desa Mengkirau Kecamatan Merbau).

UU No. 20 Tahun 2008. UU No. 20 Tahun 2008. , UU No. 20 Tahun $2008 \S$ (2008).

KBBI (2017, Desember 5). Retrieved from KBBI Daring: https://kbbi.kemdikbud.go.id/entri/jur nal 